Journal of Architectural Research and Development

Review Article

\title{
Research on the Application of Green Design Concept in Interior Design
}

Lu Zhang

Zibo Vocational Institute, Zibo 255314, Shandong Province, China

Abstract: In recent years, with the rapid development of China's economy and the accelerating process of urbanization, China's construction industry has advanced by leaps and bounds, driving the building decoration industry into a golden period. As the key to urban construction and sustainable social development, the green concept has become a key requirement for the living environment of urban and rural residents, and the green concept and green life have become socially conscious. At present, green design has been widely used in the design and construction stage, but there are still many designers do not pay enough attention to it. Therefore, through the application of green design concept in interior design research, it is beneficial to realize the building indoor and outdoor ecological environmental protection as well as energy conservation and emission reduction, so as to fully meet the owner's green ecological requirements for the indoor environment, and thus promote the healthy development of China's building decoration industry.

Keywords: Green design; Green building; Green life

Publication date: July, 2020

Publication online: 31 July, 2020

*Corresponding author: Lu Zhang,dmiss@126.com

Green design patterns not only conform to the trend of the times, but also meet the needs of people for a green and stable living environment. The green concept is a design philosophy used to protect all ecological resources that balance the relationship between man and nature, while maximizing the conservation of natural resources. With the improvement of people's quality of life and the implementation of the concept of energy conservation and environmental protection, green design has set off a new design boom in the field of interior design ${ }^{[1]}$.

Green building and green design are inevitable trends in the development of the construction industry. Integrating green concepts into design and construction creates a comfortable and safe environment for people while also ensuring that it is an ecologically friendly low-carbon environment. Integrating green concepts into the built environment and combining interior design with green design can help people improve their environmental protection concepts and enhance their quality of life.

\section{Meaning of green design}

The concept of green design has evolved since the late 19th century. At the end of the 19th century, designers around the world gradually abandoned traditional design concepts and actively explored innovative design ideas. By the end of the 20th century, most designers began to change their design styles and design ideas, exploring interior design from a deeper direction and perspective, hoping to connect human design concepts and design elements with the nature of the world to form a green design concept of sustainable development ${ }^{[2]}$.

Green design is an effective way to solve the increasingly serious environmental pollution problem. It can, to a certain extent, reduce the pollution of the interior decoration ecology and indoor environment, create a healthy and environmentally friendly living environment for users, and protect people's physical and mental health. The concept of green design covers all design fields, and its application is very broad. In the process of interior design, it is necessary to consider a variety of factors, such as decorative materials and 
construction techniques, and the effect of interior design is mostly constrained by these factors, so it cannot meet the quality standards and requirements established in the design, which leads to more serious pollution problems and energy consumption. Therefore, the application of green design concepts to interior design is an inevitable trend in the development of the construction industry. We need to do a good job of saving resources and energy from multiple perspectives to improve the environmental protection level of buildings, thus promoting the green and healthy development of interior design.

\section{Green design basic principles}

\subsection{The principle of individualization}

The creation and application of green design is consistent with national sustainable development strategies. By practicing green design, we are contributing to improving energy efficiency and reducing environmental pollution. However, interior design is not static, due to people's different lifestyles, habits and cultural quality level, there is still a great difference in the requirements of interior design. Therefore, the application of green landscape design concepts to interior design should follow the principle of individuality, meet the environmental and energysaving needs of users for interior design, and match the aesthetics and values of users. We can't generalize, before the design need to fully investigate, understand the user's individual needs, only through "personalized" to get a better design identity ${ }^{[3]}$.

\subsection{Eco-friendly principle}

The core of the green design concept is "green", including green interior decoration materials, green interior building technology and green interior landscape design. Therefore, in the process of applying the green design concept to interior design, not only should we consider the environmental protection of the interior design surface, but also need to design indoor space layout according to the material and energy consumption of the building itself, and incorporate design innovation into green design. Create a good indoor ecological environment, improve the quality of life and experience of users, meet the ecological and environmental needs of interior design, and achieve the ultimate goal of the green design concept.

\subsection{Economic principle}

Applying green design concepts to interior design not only meets the individual user's needs, but should also be consistent with the economic benefits of energy conservation and emission reduction. In other words, choose environmentally friendly low-cost building materials, advanced scientific building technology, and use low-energy construction equipment to reduce the total cost of interior design and construction, and achieve energy savings without affecting the design effect and construction quality. In particular, when selecting building materials, scientific choices should be made based on the user's personal preferences and economic situation. We need to ensure that the building materials are not only economical, but also green. In order to strike a balance between the two, designers must invest a lot of energy and time in the design phase.

\section{The application of green concepts in interior environmental design}

\subsection{Green space layout}

In current interior design, while designers are able to incorporate green design concepts into their designs, the depth of implementation is relatively shallow. The goal of the interior designer is to make the design more valuable, to apply green design techniques to the design of the space, and to make people more comfortable living in that space.

The so-called green space is to provide a reasonable space for behavior, the first should fully consider the human experience in the space, and deal with the relationship between the spatial scale and people, to meet the functional and formal needs of the space, focusing on the psychological feelings of people. The size and shape of the spatial scale will give people in this environment with different feelings, the space will be too large to make the space appear empty, people will have the psychological feeling of fear; space is too small will give people a sense of oppression, making people feel a sense of pressure. Therefore, green space design should focus on considering the psychological feelings of people in the space, according to different places, combined with the psychological needs of people to design applicable space scale.

\subsection{Application of green materials}

Green design is not only applied in the design stage, but also in the material selection and construction stages. Design is not an art on paper. If we only pursue 
the design effect and ignore the construction process, the project will not be realized and the meaning of green design will be lost. For example, in the actual construction process, in order to pursue greater profits, some projects will still use some materials with strong chemical composition, resulting in indoor harmful gases exceed the standard value.

Interior designers are increasingly using green materials in modern building decoration design. In recent years, the production process of green building decoration materials has developed rapidly, which effectively improves the environmental protection and energy efficiency of the indoor space while meeting the building function. For example, through the use of LDE light source, energy consumption can be effectively reduced, saving electricity consumption, on the basis of satisfying the lighting function, thus achieving the sustainable development goal of green design.

The application of green environmental protection concept in future interior design will be more and more extensive. Design should be people-oriented, designers should be green, environmental protection, energy saving and other factors into the whole process of design and construction. Therefore, the use of green environmental protection materials in the design of the interior environment is particularly important.

\subsection{Green regeneration and recycling}

The concept of green design should fully consider the principle of sustainable development, design renewable and recyclable building materials and processes. Interior design should create a warm living environment, so the development of mass-produced industrialized products should also consider their "emotional" design.

In the interior design and construction process should be integrated into the green design concept, in the design phase must be fully considered interior design materials, to ensure that the design of decorative materials with green features and standards. In the selection of decoration materials should also consider choosing some biodegradable, renewable materials as decorative materials, and strictly control its quality ${ }^{[4]}$.

Building decoration projects produce a large number of wood cubes, boards and other waste materials, remnants and old materials, which is a great waste if they are directly removed. Recycled waste wood can be recycled and regenerated through some ingenious and creative designs. For example, the wood can be cut into evenly spaced pieces, and the wall studs can be used to create tree branches to create a themed wall.
Furthermore, the board can be made into a variety of shelves, can be placed to meet the function of items at the same time, to achieve the recycling and reuse of waste wood.

\subsection{Integration of green design concept and specific method implementation}

The green design philosophy, as an important theoretical basis for interior design, must also be implemented in an effective way. Designers need to use as many green materials as possible in their designs and achieve the desired effect in a simple way to reduce waste and resource pollution. In practice, the design concept must be integrated with a particular method of achieving the design. For example, in the design of interior space, the solid wall can be opened and replaced by a large glass curtain wall, using the technique of "borrowing scenery" to bring the outdoor environment indoors, so as to achieve communication and integration of the indoor and outdoor environment. This will not only bring greenery indoors, but also increase the lighting surface, which is conducive to ventilation and air exchange. This not only provides the occupants with a comfortable living environment, but also satisfies their needs for a green environment and spirituality, which is in line with the green design concept.

\section{Conclusion}

The application of green design concept in interior design is the objective need of sustainable and healthy development of building decoration industry. The traditional high energy consumption design method will be gradually eliminated by social progress. The green design concept not only conforms to the trend of the times, but also satisfies people's demand for a green, healthy and stable living environment. In the design process, it is necessary to follow the application principles and methods of green design. From the optimization of indoor space layout, selection of green and renewable building materials and other aspects, to meet the material and spiritual needs of users for the living environment. By promoting the continuous innovation of green design concept, the sustainable development of green design will be promoted to improve people's living environment and enhance economic and social benefits.

\section{References}


[1] Warm. Research on the Application of Green Design Concept in Interior Environmental Design [D]. Wuhan University of Technology, 2018.

[2] Li H. The application of green design concept in interior design[J]. Stage, 2015(12): 45-46.
[3] Zhao FL. Analysis of the application of "green" design concept in interior design[J]. Modern Decoration(Theory), 2015(1): 51.

[4] Kang XW. The application of green design concept in interior design[J]. Green Building,2013, 5(5): 46-47. 